\title{
Pengaruh Reformasi Administrasi Perpajakan Terhadap Kepatuhan Wajib Pajak Orang Pribadi (Studi Kasus Pada Kantor Pelayanan Pajak (KPP) Pratama Sumedang)
}

\author{
Fahrul Alam Masruri \\ STIE Sebelas April Sumedang \\ Jalan Angkrek Situ No.19 Sumedang \\ email: masruri2012af@gmail.com
}

\begin{abstract}
ABSTRAK
Penelitian ini dilatarbelakangi oleh digulirkannya program kegiatan oleh Direktorat Jenderal Pajak tentang reformasi administrasi perpajakan jangka menengah (3-5 tahun). Reformasi administrasi perlu dilakukan untuk tercapainya tingkat kepatuhan yang tinggi mengingat masih rendahnya peningkatan kepatuhan wajib pajak orang pribadi dari tahun ke tahun di Kabupaten Sumedang ini. Penelitian bertujuan untuk mengetahui bagaimana pengaruh reformasi administrasi perpajakan terhadap kepatuhan wajib pajak orang pribadi. Metode yang digunakan dalam penelitian ini adalah metode survei dengan pendekatan deskriptif analisis, dengan pengambilan sampel menggunakan rumus Slovin. Teknik pengumpulan data menggunakan wawancara, observasi dan studi literatur. Analisis data dilakukan secara kuantitatif dengan menggunakan uji korelasi product moment dan uji $f$. Hasil penelitian diperoleh nilai koefisien korelasi -0,261 dan derajat determinasi pengaruh reformasi administrasi perpajakan terhadap kepatuhan wajib pajak sebesar 6,8\% sedangkan 93,2\% dipengaruhi faktor lain. Hasil pengujian hipotesis diperoleh nilai fhitung lebih besar dari ftabel (f hitung $4,964>f_{\text {tabel }} 3,998$ ) sehingga hipotesis diterima atau terdapat pengaruh reformasi administrasi perpajakan terhadap kepatuhan wajib pajak orang pribadi pada KPP Pratama Sumedang.
\end{abstract}

Kata Kunci : Reformasi administrasi perpajakan, Kepatuhan wajib pajak

\section{PENDAHULUAN}

Mengingat begitu pentingnya peranan pajak, maka pemerintah dalam hal ini Direktorat Jenderal Pajak di bawah naungan Kementerian Keuangan telah melakukan berbagai upaya strategis untuk memaksimalkan penerimaan pajak. Salah satu upaya yang dilakukan adalah melalui reformasi perpajakan dengan diberlakukannya self assesment system.Self assesment system merupakan 
pemungutan pajak yang memberi wewenang, kepercayaan, tanggung jawab kepada wajib pajak untuk menghitung, memperhitungkan, membayar, dan melaporkan sendiri besarnya pajak yang harus dibayar (Waluyo, 2010: 17).

Reformasi di bidang administrasi dilaksanakan melalui program modernisasi administrasi perpajakan. Eksistensi modernisasi administrasi perpajakan mencakup 4 hal utama, yaitu (i) restrukturisasi organisasi berdasarkan fungsi dan penerapan berdasarkan fungsi dan penerapan prinsip segmentasi wajib pajak, serta debirokratisasi pelayanan melalui penerapan struktur organisasi berdasarkan fungsi; (ii) penyempurnaan proses bisnis melalui optimalisasi penggunaan teknologi komunikasi dan informasi yang mengarah kepada full automation (otomatis lengkap); (iii) penyempurnaan sistem manajemen sumber daya manusia melalui pengembangan manajemen sumber daya manusia berbasis kompetensi yang berlandaskan "transparency, fairness, dan performance based"; serta (iv) penerapan Kode Etik Pegawai secara tegas pada semua lini organisasi untuk menjamin terwujudnya pelaksanaan "good governance".

Reformasi pajak sebenarnya lebih diarahkan pada upaya untuk meningkatkan kepatuhan wajib pajak, terutama dalam hal pembayaran pajak. Wajib pajak patuh bukan berarti wajib pajak yang membayar pajak dalam nominal besar, melainkan wajib pajak yang mengerti dan mematuhi hak dan kewajibannya dalam bidang perpajakan serta telah memenuhi kriteria-kriteria tertentu. Pemerintah telah berusaha keras untuk meningkatkan kesadaran masyarakat dalam membayar pajak. Hal ini bisa dilihat dari peningkatan penerimaan Negara dari sektor pajak.

Kepatuhan pajak merupakan salah satu kendala yang dapat menghambat keefektivan pengumpulan pajak. Agar target pajak tercapai, perlu ditumbuhkan secara terus menerus kepatuhan dan kesadaran masyarakat untuk memenuhi kewajiban perpajakan. Menurut Murray dalam Fitriah (2011:5) menyatakan bahwa "rendahnya kepatuhan Wajib Pajak dapat disebabkan oleh banyak hal, tetapi yang paling utama adalah karena tidak adanya data tentang Wajib Pajak yang dapat digunakan untuk mengetahui kepatuhannya". Sedangkan ketidakpatuhan tersebut terlihat dari adanya gap antara jumlah Wajib Pajak Orang Pribadi terdaftar yang menyampaikan SPT dan jumlah SPT yang dilaporkan ke Kantor Pelayanan Pajak sehingga tingkat kepatuhan dinilai masih relatif rendah.

Pada Kantor Pelayanan Pajak (KPP) Pratama Sumedang, terdapat fenomena kepatuhan yang rendah khususnya kepatuhan wajib pajak orang pribadi. Data mengenai hal tersebut adalah sebagai berikut: 
Tabel 1. Rasio Kepatuhan Penyampaian SPT Tahunan Wajib Pajak Orang Pribadi KPP Pratama Sumedang

\begin{tabular}{|l|l|l|l|l|l|}
\hline Uraian & 2012 & 2013 & 2014 & 2015 & 2016 \\
\hline $\begin{array}{l}\text { Wajib pajak orang } \\
\text { pribadi yang } \\
\text { terdaftar wajib } \\
\text { pajak SPT }\end{array}$ & 78.740 & 89.817 & 65.175 & 66.683 & 71.024 \\
\hline SPT tahunan PPh & 35.090 & 35.034 & 31.876 & 30.977 & 42.178 \\
\hline Rasio kepatuhan & $44,56 \%$ & $27,22 \%$ & $49,91 \%$ & $46,45 \%$ & $59,38 \%$ \\
\hline
\end{tabular}

Sumber : seksi pengolahan data dan informasi KPP Pratama Sumedang

Rendahnya tingkat kepatuhan wajib pajak orang pribadi pada KPP Pratama Sumedang disebabkan oleh beberapa hal, diantaranya wajib pajak orang pribadi kurang mengerti tata cara mendaftarkan diri dan persyaratan untuk memperoleh Nomor Pokok Wajib Pajak (NPWP), masih rendahnya wajib pajak orang pribadi yang menyetorkan kembali SPT tahunannya, wajib pajak yang menggunakan sistem Self Assessment belum sepenuhnya memahami cara perhitungan dan pembayaran pajak terutang, dan masih banyak wajib pajak orang pribadi yang melakukan pembayaran pajak terutang pada waktu jatuh tempo.

Berdasarkan latar belakang diatas penulis tertarik untuk membahas permasalahan mengenai pengaruh reformasi administrasi perpajakan terhadap kepatuhan wajib pajak, dengan objek penelitian pada KPP Pratama Sumedang. Maka penulis dalam penelitian ini mengambil judul : "PENGARUH REFORMASI ADMINISTRASI PERPAJAKAN TERHADAP KEPATUHAN WAJIB PAJAK ORANG PRIBADI (Studi Kasus Pada Kantor Pelayanan Pajak (KPP) Pratama Sumedang)"

\subsection{Rumusan masalah}

1. Bagaimana reformasi administrasi perpajakan pada KPP Pratama Sumedang.

2. Bagaimana tingkat kepatuhan wajib pajak orang pribadi pada KPP Pratama Sumedang.

3. Bagaimana pengaruh reformasi administrasi perpajakan terhadap kepatuhan wajib pajak orang pribadi pada KPP Pratama Sumedang.

1.3 Tujuan penelitian

1. Untuk mengetahui reformasi administrasi perpajakan pada KPP Pratama Sumedang.

2. Untuk mengetahui tingkat kepatuhan wajib pajak orang pribadi pada KPP Pratama Sumedang.

3. Untuk mengetahui pengaruh reformasi administrasi perpajakan terhadap kepatuhan wajib pajak orang pribadi pada KPP Pratama Sumedang.

\section{Tinjauan Pustaka}

Berdasarkan Ketentuan Umum dan Tata Cara Perpajakan (Direktorat Jenderal Pajak, 2013: 4): "Pajak adalah kontribusi wajib kepada negara yang terutang 
oleh orang pribadi atau badan yang bersifat memaksa berdasarkan UndangUndang, dengan tidak mendapatkan imbalan secara langsung dan digunakan untuk keperluan negara bagi sebesar-besarnya kemakmuran rakyat." Sementara itu tata cara pemungutan Pajak adalah sebagai berikut:

1. Asas-asas Pemungutan Pajak

Menurut Waluyo dan B. Ilyas dalam Fitriah (2011 : 12) asas-asas pemungutan pajak sebagaimana dikemukakan oleh Adam Smith dalam buku An inquiri into the Nature ang Cause of the Wealth of Nations menyatakan bahwa "pemungutan pajak hendaknya didasarkan pada Equality, Certainty, Convenience, dan Economy."

2. Sistem Pemungutan Pajak

Dalam memungut pajak dikenal beberapa sistem pemungutan pajak, yaitu official assesment system, self assesment system, dan with holding system (Resmi dalam Fitriah, 2011: 13).

Menurut Resmi dalam Fitriah (2011: 14) menyatakan bahwa "wajib pajak adalah orang pribadi atau badan yang menurut ketentuan peraturan perundangundangan perpajakan ditentukan untuk melakukan kewajiban perpajakan, termasuk pemungutan pajak atau pemotongan pajak tertentu".

Menurut Nasucha dalam Angkoso (2010 : 20) menyatakan bahwa: Reformasi administrasi perpajakan adalah penyempurnaan kinerja administrasi, baik secara individu, kelompok, maupun kelembagaan agar lebih efisien, ekonomis dan cepat. Agar reformasi administrasi perpajakan dapat berhasil, dibutuhkan:

a. Struktur pajak disederhanakan untuk kemudahan, kepatuhan, dan administrasi.

b. Strategi reformasi yang cocok harus dikembangkan.

c. Komitmen politik yang kuat terhadap peningkatan administrasi perpajakan.

Dimensi Reformasi Perpajakan, adalah sebagai berikut:

a. Struktur Organisai

b. Prosedur Organisasi

c. Strategi Organisasi

d. Budaya Organisasi

Menurut Budiatmanto dalam Angkoso (2010: 42) berpendapat bahwa"kepatuhan wajib pajak adalah perilaku wajib pajak dalam memenuhi kewajiban perpajakannya sesuai dengan peraturan yang berlaku". Jadi kepatuhan wajib pajak dapat diartikan sebagai tunduk, taat dan patuhnya wajib pajak dalam melaksanakan hak dan kewajiban perpajakannya sesuai dengan ketentuan perundang-undangan perpajakan yang berlaku. Menurut Nurmantu dalam Fitriah (2011 :25) mengatakan bahwa "kepatuhan perpajakan dapat didefinisikan sebagai suatu keadaan di mana wajib pajak dalam memenuhi semua kewajiban perpajakan dan melaksanakan hak perpajakannya". Terdapat dua macam kepatuhan, yakni: kepatuhan formal dan kepatuhan material (Ony dalam Fitriah $2011: 25)$. 


\subsection{Kerangka Pemikiran}

Tabel 2. Paradigma Penelitian

\begin{tabular}{|l|l|}
\multicolumn{1}{|c|}{ Variabel X } \\
\multicolumn{1}{|c|}{ Reformasi Administrasi Perpajakan }
\end{tabular}

Sumber: Nasucha dalam Angkoso (2010)

\section{METODE PENELITIAN}

Penelitian ini merupakan penelitian yang menggunakan metode survey pendekatan deskriptif analisis. Menurut Sugiyono (2012:11) yang dimaksud metode survey adalah: "Metode survey yaitu metode penelitian yang dilakukan pada populasi besar maupun kecil, tetapi data yang dipelajari adalah data dari sampel yang diambil dari populasi tersebut, sehingga ditemukan kejadiankejadian relatif, distribusi, dan hubungan-hubungan antara variabel sosiologis maupun psikologis".

\subsection{Tempat dan Waktu Penelitiaan}

Tempat yang dijadikan objek penelitian oleh penulis adalah Kantor Pelayanan Pajak (KPP) Pratama Sumedang yang beralamat di Jl. Ibrahim Adjie No. 371 Bandung. Penelitian dilaksanakan pada bulan Maret, April, Mei tahun 2017.

\subsection{Desain Penelitian}

Menurut Sugiyono (2012: 86) "Desain penelitian adalah menjabarkan berbagai variabel yang akan diteliti kemudian membuat pengaruh antara satu variabel terhadap variabel lainnya, shingga akan mudah dirumuskan masalah penelitian, instrumen penelitian, teknik analisis dan kesimpulan yang diharapkan".

\subsection{Operasionalisasi Variabel}

Tabel 3. Operasionalisasi Variabel

\begin{tabular}{|c|c|c|c|c|}
\hline \multirow[b]{2}{*}{\begin{tabular}{|l|}
\multicolumn{1}{|c|}{ Variabel } \\
Reformasi \\
Administrasi \\
Perpajakan \\
(X)
\end{tabular}} & Konsep & Dimensi & Indikator & Skala \\
\hline & $\begin{array}{l}\text { Menurut Nasucha } \\
\text { dalam Angkoso } \\
(2010: 18) \text {, } \\
\text { reformasi } \\
\text { administrasi } \\
\text { perpajakan adalah } \\
\text { penyempurnaan } \\
\text { atau perbaikan }\end{array}$ & $\begin{array}{l}\text { 1. Struktur } \\
\text { Organisasi }\end{array}$ & $\begin{array}{l}\text { 1. Pembenahan } \\
\text { fungsi } \\
\text { pelayanan dan } \\
\text { pemeriksaan }\end{array}$ & $\begin{array}{l}\text { Inter } \\
\text { val }\end{array}$ \\
\hline & & & Fahrul Alam & 1127 \\
\hline
\end{tabular}


ISSN

2460-030X

\begin{tabular}{|c|c|c|c|c|}
\hline & $\begin{array}{l}\text { kinerja } \\
\text { administrasi, baik } \\
\text { secara individu, } \\
\text { kelompok, } \\
\text { maupun } \\
\text { kelembagaan agar } \\
\text { lebih efisien, } \\
\text { ekonomis dan } \\
\text { cepat. Agar } \\
\text { reformasi } \\
\text { administrasi } \\
\text { perpajakan dapat } \\
\text { berhasil, } \\
\text { dibutuhkan: } \\
\text { 1. Struktur pajak } \\
\text { disederhanakan } \\
\text { untuk kemudahan, } \\
\text { kemunan } \\
\text { kepatuhan, dan } \\
\text { administrasi. } \\
\text { 2. Strategi } \\
\text { reformasi yang } \\
\text { cocok harus } \\
\text { dikembangkan } \\
\text { 3. Komitme } \\
\text { n politik yang } \\
\text { kuat terhadap } \\
\text { peningkatan } \\
\text { administrasi } \\
\text { perpajakan }\end{array}$ & $\begin{array}{l}\text { 3. Strategi } \\
\text { Organisasi }\end{array}$ & $\begin{array}{l}\text { Peraturan } \\
\text { 3. Pendelegasian } \\
\text { otoritas } \\
\text { kegiatan } \\
\text { 4. Sistem } \\
\text { pelaporana } \\
\text { secara rutin } \\
\text { 5. Jalur } \\
\text { pengawasan } \\
\text { tugas. } \\
\text { 6. Pemahaman } \\
\text { terhadap misi } \\
\text { dan tanggung } \\
\text { jawab } \\
\text { organisasi } \\
\\
\text { 7. Informasi } \\
\text { perpajakan } \\
\text { 8. Penyederha- } \\
\text { naan formulir } \\
\text { dan prosedur } \\
\text { pelayanan. }\end{array}$ & \\
\hline $\begin{array}{l}\text { Kepatuhan } \\
\text { Wajib Pajak } \\
\text { (Y) }\end{array}$ & 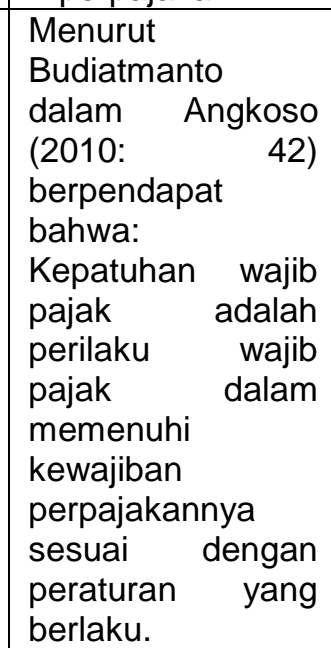 & $\begin{array}{l}\text { 1. Kepatuhan } \\
\text { Formal }\end{array}$ & 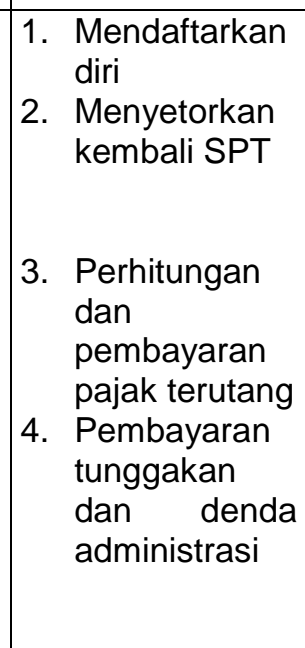 & $\begin{array}{c}\text { Inter } \\
\text { val }\end{array}$ \\
\hline
\end{tabular}




\subsection{Teknik Pengumpulan Data}

Populasi dalam penelitian ini adalah wajib pajak orang pribadi yang terdaftarpada KPP Pratama Sumedang pada tahun 2016.Adapun jumlah populasi yang diteliti tersebut yaitu sebanyak 71.024 orang.

Dalam penelitian ini, untuk menghitung jumlah sampel yang akan digunakan penulis menggunakan rumus slovin. Jumlah sampel yang akan digunakan oleh peneliti adalah sebanyak 70 responden dengan metode random sampling yakni pengambilan sampel dari populasi secara acak.

\section{HASIL PENELITIAN DAN PEMBAHASAN}

\subsection{OBJEK PENELITIAN}

Kantor Pelayanan Pajak (KPP) Pratama adalah kantor yang khusus melayani pelaporan dalam perpajakan, sangat membantu para Wajib Pajak untuk memenuhi kewajibannnya yaitu membayar pajak. Kantor Pelayanan Pajak (KPP) Pratama Sumedang merupakan kantor pembentukan baru sejak tanggal 28 Agustus 2007 sesuai dengan Peraturan Menteri Keuangan Nomor 55/PMK.01/2007 tentang Organisasi dan Tata Kerja Instansi Vertikal Direktorat Jenderal Pajak. KPP Pratama Sumedang merupakan pemecahan dari Kantor Pelayanan Pajak Karees dan Kantor Pelayanan Pajak Bumi dan Bangunan Garut.

Kantor Pelayanan Pajak (KPP) Pratama adalah instansi vertikal Direktorat Jenderal Pajak yang berada dibawah pengawasan dan bimbingan Kantor Wilayah DJP Jawa Barat I yang mempunyai tugas melaksanakan pelayanan bidang Perpajakan dengan pelayanan kelas dunia dengan penerapan sistem administrasi modern, serta berusaha menerapkan trisukses yaitu sukses data, sukses pelayanan, dan sukses penerimaan, dalam mendukung tercapainya sasaran, dan mengamankan tugas-tugas lain yang diamanatkan oleh APBN.

\subsection{Analisis Data}

Tabel 4.Penilaian Variabel Reformasi Administrasi Perpajakan (X)

\begin{tabular}{|c|c|c|c|c|c|c|c|c|c|}
\hline $\begin{array}{c}\text { No. } \\
\text { Item }\end{array}$ & 5 & 4 & 3 & 2 & 1 & Jumlah & $\begin{array}{c}\text { Skor } \\
\text { empirik }\end{array}$ & $\begin{array}{c}\text { Skor } \\
\text { max }\end{array}$ & $\begin{array}{c}\text { Capaian } \\
\%\end{array}$ \\
\hline 1 & 43 & 13 & 14 & & & 70 & 309 & 350 & 88.3 \\
\hline 2 & 18 & 48 & 25 & & & 70 & 294 & 350 & 84 \\
\hline 3 & 36 & 25 & 9 & & & 70 & 307 & 350 & 87.7 \\
\hline 4 & 17 & 40 & 11 & 2 & & 70 & 282 & 350 & 80.6 \\
\hline 5 & 31 & 28 & 9 & 2 & & 70 & 298 & 350 & 85.1 \\
\hline 6 & 20 & 38 & 11 & 1 & & 70 & 287 & 350 & 82 \\
\hline 7 & 28 & 27 & 14 & 1 & & 70 & 292 & 350 & 83.4 \\
\hline 8 & 20 & 35 & 12 & 3 & & 70 & 282 & 350 & 80.6 \\
\hline
\end{tabular}


ISSN

2460-030X

Jurnal Akuntansi Bisnis dan Ekonomi

Volume 4 No. 2, September 2018

\begin{tabular}{|c|c|c|c|c|c|c|c|c|c|}
\hline 9 & 27 & 28 & 14 & 1 & & 70 & 291 & 350 & 83.1 \\
\hline 10 & 23 & 36 & 11 & & & 70 & 292 & 350 & 83.4 \\
\hline 11 & 31 & 30 & 8 & 1 & & 70 & 301 & 350 & 86 \\
\hline 12 & 27 & 21 & 20 & 2 & & 70 & 283 & 350 & 80.9 \\
\hline $\begin{array}{l}\text { Skor } \\
\text { total }\end{array}$ & 321 & 369 & 158 & 13 & 0 & 840 & 3518 & 4200 & 83.8 \\
\hline
\end{tabular}

Berdasarkan tabel terlihat bahwa skor total untuk variabel reformasi administrasi perpajakan adalah 3518 dari skor harapan 4200. Penilaian responden mengenai reformasi administrasi perpajakan secara keseluruhan yang dinilai berdasarkan indikator-indikatornya berada pada kategori sangat tinggi.

Tabel 5.Penilaian Variabel Kepatuhan Wajib Pajak Orang Pribadi (Y)

\begin{tabular}{|c|c|c|c|c|c|c|c|c|c|}
\hline $\begin{array}{c}\text { No. } \\
\text { Item }\end{array}$ & 5 & 4 & 3 & 2 & 1 & Jumlah & $\begin{array}{c}\text { Skor } \\
\text { empirik }\end{array}$ & $\begin{array}{c}\text { Skor } \\
\text { max }\end{array}$ & $\begin{array}{c}\text { Capaian } \\
\%\end{array}$ \\
\hline 1 & 48 & 21 & 1 & & & 70 & 327 & 350 & 93.4 \\
\hline 2 & 38 & 32 & & & & 70 & 318 & 350 & 90.9 \\
\hline 3 & 38 & 32 & & & & 70 & 318 & 350 & 90.9 \\
\hline 4 & 27 & 41 & 2 & & & 70 & 305 & 350 & 87.4 \\
\hline 5 & 27 & 41 & 2 & & & 70 & 305 & 350 & 87.4 \\
\hline 6 & 34 & 33 & 3 & & & 70 & 311 & 350 & 88.9 \\
\hline 7 & 40 & 30 & & & & 70 & 320 & 350 & 91.4 \\
\hline 8 & 24 & 44 & 2 & & & 70 & 302 & 350 & 86.3 \\
\hline 9 & 21 & 48 & 1 & & & 70 & 300 & 350 & 85.7 \\
\hline 10 & 29 & 41 & & & & 70 & 309 & 350 & 88.3 \\
\hline 11 & 29 & 41 & & & & 70 & 309 & 350 & 88.3 \\
\hline 12 & 36 & 31 & 3 & & & 70 & 313 & 350 & 89.4 \\
\hline $\begin{array}{l}\text { Skor } \\
\text { total }\end{array}$ & 391 & 435 & 14 & 0 & 0 & 840 & 3737 & 4200 & 89 \\
\hline
\end{tabular}

Sumber: Data kuesioner setelah diolah, 2017

Berdasarkan tabel terlihat bahwa skor total untuk variabel kepatuhan wajib pajak orang pribadi adalah 3737 dari skor harapan 4200. Penilaian responden mengenai kepatuhan wajib pajak orang pribadi secara keseluruhan yang dinilai berdasarkan indikator-indikatornya berada pada kategori sangat tinggi.

\subsection{Pengujian Data}

Tabel 6. Hasil Uji Validitas Variable $\mathrm{X}$

\begin{tabular}{|c|c|c|c|}
\hline Pernyataan & R hitung & R tabel & Keterangan \\
\hline 1 & 0,333 & 0,232 & Valid \\
\hline 2 & 0,482 & 0,232 & Valid \\
\hline
\end{tabular}




\begin{tabular}{|c|c|c|c|}
\hline 3 & 0,443 & 0,232 & Valid \\
\hline 4 & 0,520 & 0,232 & Valid \\
\hline 5 & 0,280 & 0,232 & Valid \\
\hline 6 & 0,380 & 0,232 & Valid \\
\hline 7 & 0,437 & 0,232 & Valid \\
\hline 8 & 0,506 & 0,232 & Valid \\
\hline 9 & 0,545 & 0,232 & Valid \\
\hline 10 & 0,491 & 0,232 & Valid \\
\hline 11 & 0,530 & 0,232 & Valid \\
\hline 12 & 0,520 & 0,232 & Valid \\
\hline
\end{tabular}

Sumber: Data Kuesioner setelah diolah, 2017

Tabel 7. Hasil Uji Validitas Variable Y

\begin{tabular}{|c|c|c|c|}
\hline Pernyataan & R hitung & R tabel & Keterangan \\
\hline 1 & 0,489 & 0,232 & Valid \\
\hline 2 & 0,667 & 0,232 & Valid \\
\hline 3 & 0,667 & 0,232 & Valid \\
\hline 4 & 0,489 & 0,232 & Valid \\
\hline 5 & 0,489 & 0,232 & Valid \\
\hline 6 & 0,471 & 0,232 & Valid \\
\hline 7 & 0,293 & 0,232 & Valid \\
\hline 8 & 0,471 & 0,232 & Valid \\
\hline 9 & 0,334 & 0,232 & Valid \\
\hline 10 & 0,465 & 0,232 & Valid \\
\hline 11 & 0,465 & 0,232 & Valid \\
\hline 12 & 0,247 & 0,232 & Valid \\
\hline
\end{tabular}

Sumber: Data Kuesioner setelah diolah, 2017

\section{Uji Reliabilitas}

\section{Tabel 8. Hasil Uji Reliabilitas Variable X dan Variabel Y}

\begin{tabular}{|c|c|c|c|}
\hline Variabel & Cronbach Alph & N of item & Keterangan \\
\hline $\mathrm{X}$ & 0,645 & 12 & Reliabel \\
\hline $\mathrm{Y}$ & 0,702 & 12 & Reliabel \\
\hline
\end{tabular}

Sumber: Data Kuesioner setelah diolah, 2017

\section{Uji Normalitas}

Tabel 9. Hasil Uji Normalitas

\begin{tabular}{|c|c|c|}
\hline $\begin{array}{c}\text { Kolmogorov-smirnov } \\
\text { test }\end{array}$ & $\begin{array}{c}\text { Kolmogorov-smirnov } \\
\text { tabel }\end{array}$ & keterangan \\
\hline 0.171 & 0.144 & Normal \\
\hline
\end{tabular}

Sumber: Data Kuesioner setelah diolah, 2017 
ISSN

2460-030X

\section{Analisis Regresi Sederhana}

Tabel 10. Analisis Regresi Sederhana

\begin{tabular}{||c|c|c|c|c|c|}
\hline \multirow{2}{*}{ Model } & \multicolumn{2}{|c|}{$\begin{array}{l}\text { Unstandardized } \\
\text { Coefficients }\end{array}$} & $\begin{array}{c}\text { Standardized } \\
\text { Coefficients }\end{array}$ & & \\
\cline { 2 - 5 } & $\mathrm{B}$ & $\begin{array}{c}\text { Std. } \\
\text { Error }\end{array}$ & Beta & $\mathrm{t}$ & Sig. \\
\hline $1 \quad \begin{array}{l}\text { (Constant) } \\
\text { Reformasi } \\
\text { administrasi } \\
\text { perpajakan }\end{array}$ & -.206 & .092 & -.261 & -2.228 & .029 \\
\hline
\end{tabular}

a. Dependent Variable: kepatuhan wajib pajak orang pribadi

Berdasarkan tabel diatas, nilai konstanta (a) adalah sebesar 39,940, sedangkan nilai (b) adalah $-0,206$ sehingga persamaan regresinya dapat ditulis:

$$
\bar{Y}=a+b X \text { atau } \bar{Y}=39,940+(-0,206) X
$$

Tabel 11. Hasil Uji Korelasi

\begin{tabular}{|ll|r|r|}
\hline & $\begin{array}{c}\text { Reformasi } \\
\text { administrasi } \\
\text { perpajakan }\end{array}$ & $\begin{array}{c}\text { Kepatuhan wajib } \\
\text { pajak orang pribadi }\end{array}$ \\
\hline Reformasi & Pearson Correlation & 1 & -.261 \\
administrasi & Sig. (2-tailed) & 70 & .029 \\
perpajakan & $\mathrm{N}$ & $-.261^{\circ}$ & 70 \\
\hline Kepatuhan wajib & Pearson Correlation & .029 & 1 \\
pajak orang pribadi & Sig. (2-tailed) & 70 & 70 \\
& $\mathrm{~N}$ & & \\
\hline
\end{tabular}

*. Correlation is significant at the 0.05 level (2-tailed).

Berdasarkan tabel diatas, diperoleh harga $\mathrm{r}_{\mathrm{xy}}$ sebesar $-0,261$ maka hasilnya ada pada klasifikasi rendah, karena berada pada klasifikasi -0,20 - -0,399. 
Tabel 12. Hasil Uji T

\begin{tabular}{|c|c|c|c|c|c|c|}
\hline \multirow[b]{2}{*}{ Mode } & & \multicolumn{2}{|c|}{$\begin{array}{l}\text { Unstandardized } \\
\text { Coefficients }\end{array}$} & $\begin{array}{c}\text { Standardized } \\
\text { Coefficients }\end{array}$ & \multirow[b]{2}{*}{$\mathrm{t}$} & \multirow[b]{2}{*}{ Sig. } \\
\hline & & $B$ & Std. Error & Beta & & \\
\hline \multirow[t]{2}{*}{1} & (Constant) & 39.940 & 3.512 & & 11.373 & .000 \\
\hline & $\begin{array}{l}\text { Reformasi } \\
\text { administrasi } \\
\text { perpajakan }\end{array}$ & -.206 & .092 & -.261 & -2.228 & .029 \\
\hline
\end{tabular}

a. Dependent Variable: kepatuhan wajib pajak orang pribadi

Berdasarkan tabel diatas diketahui bahwa nilai $\mathrm{t}_{\text {hitung }}$ adalah sebesar -2,228. Sedangkan nilai ttabei pada taraf signifikan 0,05 $(\alpha=5 \%)$ dan derajat kebebasan $(\mathrm{dk})=70-2=68$ adalah 1,9955. Dengan demikian $\mathrm{t}_{\text {hitung }}$ lebih besar dari $\mathrm{t}_{\text {tabel }}$ ( $t_{\text {hitung }}-2,228>t_{\text {tabel }} 1,9955$ ) sehingga variabel $X$ terdapat pengaruh terhadap variabel $\mathrm{Y}$.

Tabel 13. Model Summary ${ }^{b}$

\begin{tabular}{|l|r|r|r|c|}
\hline Model & $\mathrm{R}$ & R Square & $\begin{array}{c}\text { Adjusted R } \\
\text { Square }\end{array}$ & $\begin{array}{c}\text { Std. Error of the } \\
\text { Estimate }\end{array}$ \\
\hline 1 & $.261^{\mathrm{a}}$ & .068 & .054 & 3.74205 \\
\hline
\end{tabular}

a. Predictors: (Constant), reformasi.administrasi.perpajakan

b. Dependent Variable: kepatuhan.wajib.pajak.orang.pribadi

Berdasarkan tabel diatas, besarnya hubungan antara reformasi administrasi perpajakan dengan kepatuhan wajib pajak orang pribadi dapat dilihat pada kolom $\mathrm{R}$ Square yaitu sebesar $6,8 \%(0,068 \times 100 \%=6,8 \%)$, artinya variabel kepatuhan wajib pajak orang pribadi $(Y)$ dipengaruhi oleh variabel reformasi administrasi perpajakan (X) sebesar 6,8 \% sedangkan sisanya sebesar 93,2 \% dipengaruhi oleh faktor lain yang tidak diteliti oleh penulis dalam penelitian ini. 
Tabel 14. ANOVA (Analysis Of Variance)

\begin{tabular}{|rl|r|r|r|r|r|}
\hline \multicolumn{1}{|l|}{ Model } & \multicolumn{1}{|c|}{$\begin{array}{c}\text { Sum of } \\
\text { Squares }\end{array}$} & df & Mean Square & F & \multicolumn{1}{c|}{ Sig. } \\
\hline 1 & Regression & 69.513 & 1 & 69.513 & 4.964 & $.029^{\mathrm{a}}$ \\
& Residual & 952.197 & 68 & 14.003 & & \\
& Total & 1021.710 & 69 & & & \\
\hline
\end{tabular}

a. Predictors: (Constant), reformasi administrasi perpajakan

b. Dependent Variable: kepatuhan wajib pajak orang pribadi

Berdasarkan tabel diatas, diperoleh nilai $\mathrm{f}_{\text {hitung }}$ sebesar 4,964.Sedangkan besar $\mathrm{f}_{\text {tabel }}$ pada taraf signifikasi $0,05(\alpha=5 \%)$ dan derajat kebebasan $(\mathrm{dk})=70-1=$ 69 , setelah dilihat dari tabel $f$ ternyata $(0,05)(69)$ tidak diperoleh dalam tabel. Untuk memperolehnya digunakan cara interpolasi.Setelah dilakukan peprhitungan tersebut,besar nilai $f$ pada taraf signifikasi $0,05(\alpha=5 \%)$ dan derajat kebebasan $(\mathrm{dk})=70-1=69$ adalah 3,998. Maka dapat disimpulkan bahwa $\mathrm{f}_{\text {hitung }}$ lebih besar dari $\mathrm{f}_{\text {tabeI }}$ ( $\mathrm{f}_{\text {hitung }} 4,964>\mathrm{f}_{\text {tabel }}$ 3,998). Sehingga hipotesis yang telah diajukan penulis diterima.

\section{KESIMPULAN}

1. Reformasi administrasi perpajakan yang dilakukan oleh KPP Pratama Sumedang diantaranya:

a. Reformasi dibidang struktur organisasi yaitu fungsi organisasi menjadi seksi organisasi.

b. Reformasi pada prosedur organisasi yaitu penyederhanaan prosedur untuk mengisi formulir Surat Setoran Pajak, dan pelaporan pajak melalui program komputerisasi, seperti pelaporan pajak (e-reporting, e-SPT on line).

c. Reformasi pada strategi organisasi yaitu mengembangkan mekanisme internal quality control atas pelaksanaan pelayanan dan pemeriksaan.

d. Reformasi budaya organisasi yang dilakukan KPP Pratama Sumedang diantaranya pembentukan komite kode etik dengan meningkatkan efektivitas, penyiapan sumber daya manusia yang berkualitas dan profesional.

Sedangkan berdasarkan pada analisis terhadap indikator reformasi administrasi perpajakan yakni struktur organisasi, prosedur organisasi, strategi organisasi dan budaya organisasi berada pada kategori tinggi.Artinya wajib pajak orang pribadi menyatakan tingkat kesetuan yang tinggi terhadap reformasi administrasi perpajakan yang dilaksanakan oleh KPP Pratama Sumedang.

2. Kepatuhan wajib pajak orang pribadi pada KPP Pratama Sumedang berada pada kategori tinggi. Karena berdasarkan pada analisis terhadap indikator 
kepatuhan wajib pajak orang pribadi yakni mendaftarkan diri untuk mendapatkan NPWP, menyetorkan kembali SPT, perhitungan dan pembayaran pajak terutang, dan pembayaran denda administrasi berada pada kategori tinggi. Artinya wajib pajak orang pribadi memiliki kecenderungan untuk kepatuhan dalam melaksanakan kewajiban perpajakan pada KPP Pratama Sumedang.

3. Reformasi administrasi perpajakan memiliki pengaruh yang rendah terhadap kepatuhan wajib pajak orang pribadi pada KPP Pratama Sumedang. Artinya dengan diadakannya reformasi administrasi perpajakan pada KPP Pratama Sumedang menyebabkan adanya peningkatan kepatuhan wajib pajak orang pribadi untuk melakukan kewajiban perpajakannya meskipun presentasenya rendah.

\section{DAFTAR PUSTAKA}

Aminah, Siti.2014. "Pengaruh Penerapan Sistem Administrasi Perpajakan Modern Terhadap Kepatuhan Wajib Pajak Pada Kantor Pelayanan Pajak (KPP) Pratama Kota Surakarta". Universitas Muhammadiyah Surakarta.

Angkoso, Berly. 2010. "Pengaruh Reformasi Administrasi Perpajakan, Pengetahuan Dasar Wajib Pajak Tentang Perpajakan, Dan Kesadaran Perpajakan terhadap Kepatuhan Wajib Pajak (Studi Empiris: Kantor Pelayanan Pajak Pratama di Wilayah Jakarta Selatan)". UIN Syarif Hidayatullah Jakarta.

Departemen Pendidikan Nasional.2010. Kamus Besar Bahasa Indonesia Edisi Ketiga. Jakarta: Balai Pustaka.

Fitriah.2011. "Analisis Pengaruh Reformasi Administrasi Perpajakan terhadap Kepatuhan Wajib Pajak Pada Kantor Pelayanan Pajak (KPP) Jakarta Tanah Abang Satu".UIN Syarif Hidayatullah Jakarta.

Lubis, Irwansyah. 2011. "Hukum Pajak Indonesia”. Jakarta: YP2SDM.

Kurniadi. 2014. "Pengaruh Promosi Terhadap Terhadap Minat Beli Konsumen Objek Wisata Pangjugjugan Kabupaten Sumedang".STIE Sebelas April Sumedang.

Mardiasmo.2010. "Perpajakan Edisi Revisi 2010". Yogyakarta: ANDI. Salemba Empat.

Mohammad Zain. 2008. "Manajemen Perpajakan". Edisi 3. Jakarta:

Nasucha,Chaizi Dr. 2004."Reformasi Administrasi Publik : Teori dan Praktik”. Jakarta: PT Gramedia Widiasaranalndonesia.

Nurkhasanah, Septiyani.2014. "Pengaruh Pengetahuan Perpajakan, Modernisasi Sistem Administrasi Perpajakan dan Kesadaran Wajib Pajak Terhadap Kepatuhan Wajib Pajak Pada Kantor Wilayah Direktorat Jenderal Pajak'. Universitas Negeri Yogyakarta.

Resmi, Siti. 2010. "Perpajakan: Teori dan Kasus". Jakarta: Salemba Empat.

Satriyo, Andika. 2007 . "Pengaruh Reformasi Administrasi Perpajakan Terhadap Kepatuhan Wajib Pajak PadaKantor Pelayanan Pajak (KPP) Pratama Jakartsa Setiabudi". Universitas Pembangunan Nasional "Veteran" Jakarta. 
ISSN

Jurnal Akuntansi Bisnis dan Ekonomi

2460-030X

Volume 4 No. 2, September 2018

Siti Kurnia Rahayu. 2010. "Perpajakan Indonesia”. Yogyakarta: Graha IImu.

Sugiyono. 2012. "Statistik untuk Penelitian".Bandung: Alfabeta.

Waluyo.2010. "Perpajakan Indonesia". Jakarta: Salemba Empat. 